proved itself invaluable in predicting new facts, so that it has now established itself in an almost impregnable position. Dr. Langmuir's atom, although presenting a tetrahedral aspect, is less able to adapt itself to organic compounds. A single bond, in the ordinary notation, is represented by an edge common to two cubes, a double bond by a face in common, so that an entirely different structure has to be adopted for a triple linking, and acetylene becomes one of the puzzles of the theory. It was also remarked that the model of sodium carbonate was essentially similar to that proposed by Werner, suggesting that the coordination theory might be elaborated to explain many chemical facts in place of a new hypothesis. It is probable that the study of valency will receive much attention in the near future, and that chemists will test each hypothesis thoroughly in its application to structural chemistry, which rests on an enormous mass of definitely established facts, with which a theory must be able to deal. In the meantime, the scheme of Dr. Langmuir, so clearly presented on this occasion, forms an excellent basis for discussion, and the Edinburgh meeting has served a most useful purpose in focussing attention on the difficulties, as well as on the advantages, of the proposed solution of the problem.

\section{The Study of Bird-migration}

\section{$\mathrm{T}$} HOUGH many valuable contributions have been made in recent years to our knowledge of the various phenomena associated with birdmigration, yet much remains to be accomplished.

One of the most important desiderata is to obtain definite information of a detailed nature as to the provenance of the migrants which arrive in spring, let us say, in the British Isles, and are widely or more or less locally distributed during the summer, and equally, or more widely, dispersed in their winter retreats. The same remarks apply to the numerous winter visitors: In what particular areas have they passed the summer? Do, for instance, redwings from Iceland winter with us as well as redwings from their wide-ranging summer haunts in Europe? Whence come the hosts of birds-of-passage which traverse our isles in spring en route for summer haunts in more northern lands, and return in the autumn on their way to their accustomed winter quarters? Each species comprised in these three groups of migrants is in all likelihood widely dispersed at both seasons, but as yet our knowledge is infinitesimal as to where the summer visitors to our country pass the winter, or where our winter visitors pass the summer, and we know nothing regarding either the summer or the winter haunts of the passage migrants.

In addition, more definite information is desirable as to (I) the routes followed by birds to reach their seasonal haunts; (2) whether the young seek the same summer and winter quarters as their parents; and (3) the winter retreats of the migratory section of certain British birds- - the socalled partial migrants.

The difficulty in solving these important problems may fairly be described as insurmountable in the main; but it has been proved feasible to obtain glimpses of enlightenment, and it is most desirable to add to these glimpses, which, when correlated, become important. This may be accomplished in detail by the process called " ringing," and in its broader aspects through a knowledge of the distribution of racial forms, if such forms are based on well-marked characters. The ringing method is, however, the more promising, since the data so obtained are of a definite nature; NO. 27 I I, VOL. IO8]

\section{by the Marking Method.}

and all who have the opportunity should cordially co-operate in forwarding the researches on these lines which are now being carried out.

With this end in view the University of Aberdeen instituted, in I9I0, an inquiry for "The Study of Bird-migration by the Marking Method." This work was carried on for several years as a piece of research under the general direction of Prof. J. Arthur Thomson, to whose son, Dr. Landsborough Thomson, on whom the carrying out of the investigation devolved, we are indebted for the " Results," which were recently published in The Ibis. The total number of species ringed was about roo, and the number of individual birds 27,802 . The total number of "reappearance records" (recoveries) was 879 , or 3.2 per cent. But, as in other inquiries of a similar nature, many of the recoveries, as was to be expected, were made in the vicinity of the scene of marking, and after an insignificant period of time. Information of an important nature was obtained, some of which forms a valuable contribution to our knowledge of the seasonal distribution abroad and at home of the following species-namely, the lapwing, woodcock, starling, song thrush, swallow, hedge-accentor, mallard, herring gull, and blackheaded gull. The data regarding these have been carefully analysed and studied in all their bearings, and the deductions derived therefrom are given in detail. Regarding the rest of the species diseussed, thirty-five in number, the data are not considered sufficient for such elaborate treatment, and for these brief summaries are given which afford in some cases records of considerable interest. There are also useful sections in which are discussed the purposes of bird-marking, its history, the interpretation of results, conclusions regarding bird-migration, and the value of the method of ringing, all of which are well worthy of perusal.

The University of Aberdeen is to be congratulated on its enlightened action in fostering this special piece of research, which, thanks to the labours and skilful treatment of one of its alumni, backed by the assistance of a number of enthusiasts, also alumni, has, greatly to his credit, been brought to a successful issue. W. E. C. 